\title{
An analytical study of intraoperative, immediate post-operative and perinatal complications in previous two caesarean section
}

\author{
Prachi Singh, Ritika Agarwal*, Shweta Yadav
}

Department of Obstetrics and Gynecology, Teerthanker Mahaveer Medical college and Research Centre, Moradabad, Uttar Pradesh, India

Received: 02 August 2018

Accepted: 01 September 2018

\author{
*Correspondence: \\ Dr. Ritika Agarwal, \\ E-mail: drritika2@yahoo.com
}

Copyright: (c) the author(s), publisher and licensee Medip Academy. This is an open-access article distributed under the terms of the Creative Commons Attribution Non-Commercial License, which permits unrestricted non-commercial use, distribution, and reproduction in any medium, provided the original work is properly cited.

\begin{abstract}
Background: Lower segment caesarean section is one of the commonest operations performed now a day.It has been seen that in cases with previous caesarean section there is increased maternal morbidity and mortality due to placenta previa, adherent placenta and caesarean hysterectomy.The present study was conducted to know the fetomaternal outcome and intra and immediate post-operative complications in cases with previous two lower segment caesarean section.

Methods: The present study was conducted in TMMC Moradabad between January 2017-January 2018.Total 68 cases were previous two lower segment caesarean section were included in the study. Neonatal outcome and intraoperative and immediate postoperative complications were seen in these cases.

Results: In the present study majority of the cases were in 30-34 years age group $(39.7 \%)$, the maximum number of caesarean sections were done between gestational age of 37-39.6 weeks (47.1\%). Intraoperatively adhesions between uterus, anterior abdominal wall and bladder was seen in less than half of the cases i.e. in $42.6 \%$ cases. Out of 68 cases with previous two lower segment caesarean operated 13 cases had placenta previa and 4 cases had adherent placenta. Conclusions: The present study shows that the maternal and perinatal morbidity and mortality is increased with increasing number of caesarean sections. So, there should be reduction in rate of primary caesarean section which can reduce the rate of placenta previa and adherent placenta in subsequent pregnancies.
\end{abstract}

Keywords: Caesarean hysterectomy, Lower segment Caesarean section (LSCS), Placenta previa

\section{INTRODUCTION}

Caesarean section is defined as birth of fetus through incision on anterior abdominal wall and uterine wall after the period of viability. Pregnancy with previous caesarean has become common now a days because of increase in the rate of primary caesarean section. There has been increase in the rate of caesarean section in India from $3 \%$ (1992) to $11 \%$ (2006). ${ }^{1,2}$ The increase in the rate of caesarean sections are due to advent of newer and safer aesthetic techniques and availability of blood, better antibiotics, more meticulous fetal monitoring and better neonatal care facilities. One of the commonest indications of caesarean section is previous caesarean section. According to one of the largest studies, serious maternal morbidity increases with increasing number of caesarean deliveries specifically from triad of placenta previa, placenta accreta and caesarean hysterectomy. $3,4,5$

The risk of complications increases with increase in the number of caesarean section due to formation of adhesions and scarring. Scar rupture in cases with previous caesarean section is another catastrophic complication. It has also been reported that complication rate is higher in emergency caesarean sections than in elective ones. ${ }^{5,6}$ The primary objective of the present 
study was to observe the fetomaternal outcome in cases with previous two lower segment caesarean section and to study the intra and immediate post-operative complications in cases with previous two lower segment caesarean section.

\section{METHODS}

The present study was conducted in Teerthankar Mahaveer Medical College between January 2017January 2018.Total 68 cases were previous two lower segment caesarean section fulfilling the inclusion criteria were included in the study.

\section{Inclusion criteria}

- All antenatal cases with previous two lower segment caesarean section getting admitted to the hospital were included in the study.

\section{Exclusion criteria}

- Patients with history of previous abdominal surgeries other than caesarean section.

- Patients with other comorbidities which can affect the fetomaternal outcome like gestational diabetes mellitus.

- Cases presenting with rupture uterus.

Detailed history regarding age, parity, detailed obstetric history, course of present pregnancy, indication of previous caesarean, antenatal, intra and post-operative complications in previous pregnancy. History of any other surgical procedure like D and C was noted.

General physical and obstetric examination was conducted. Patients were subjected to routine blood and urine investigations and ultrasonography (especially for placental localization). Patients were subjected to termination of pregnancy as per protocols. The data was entered in Microsoft Excel sheet and descriptive analysis of the data was done.

\section{RESULTS}

In the present study majority of the cases were in 30-34 years age group (39.7\%), followed by 35-39 years $(26.5 \%)$ then in $40-44$ years $(19.1 \%)$ and then in $25-29$ years $(14.7 \%)$ as depicted in Figure 1.

In majority of cases the caesarean sections were done during emergency than on elective basis (Figure 2). As depicted in table 1 the maximum number of caesarean sections were done between gestational age of 37-39.6 weeks (47.1\%), followed by between 32-36.6 weeks $(33.8 \%)$ which was followed by more than 40 weeks in $10.3 \%$ cases. Six cases presented with antepartum haemorrhage were operarted at less than 28 weeks and between 28-31.6 weeks. Intraoperatively adhesions between uterus, anterior abdominal wall and bladder was seen in less than half of the cases i.e in $42.6 \%$ cases while in $57.4 \%$ cases there were no adhesions (Table 2).

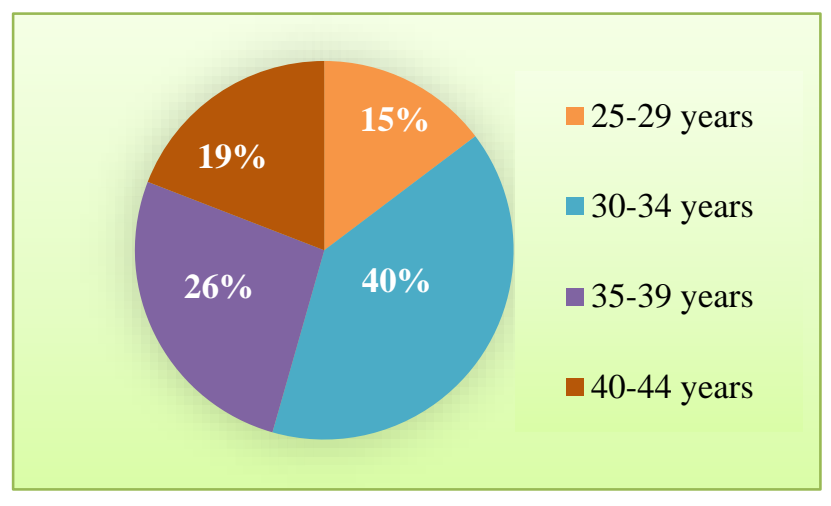

Figure 1: Distribution of cases according to age.

Out of 68 cases with previous two lower segment caesarean operated 13 cases had placenta previa and 4 cases had adherent placenta. In majority of the cases with placenta previa bleeding responded to hemostatic sutures on the placental bed while 4 cases required intrauterine packing. Out of four cases with morbidly adherent placenta 3 cases required emergency caesarean hysterectomy.

Table 1: Distribution of cases according to gestational age at time of delivery.

\begin{tabular}{|lll|}
\hline Gestational age & Number & Percentage \\
\hline$<28$ weeks & 2 & $2.9 \%$ \\
\hline 28-31.6 weeks & 4 & $5.9 \%$ \\
\hline 32-36.6 weeks & 23 & $33.8 \%$ \\
\hline 37-39.6 weeks & 32 & $47.1 \%$ \\
\hline$>40$ weeks & 7 & $10.3 \%$ \\
\hline
\end{tabular}

There was one mortality in case with morbidly adherent placenta who came in emergency with undiagnosed adherent placenta due to massive post-partum haemorrhage leading to DIC (Table 3).

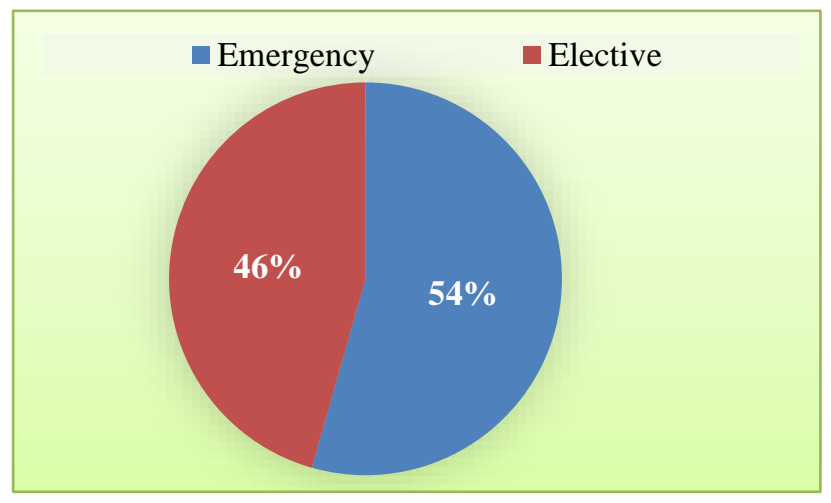

Figure 2: Distribution of cases according to timing of caesarean section.

In the intraoperative period out of 68 cases in 11 cases the previous scar was thinned out i.e in $16.1 \%$ cases. In 
the present study majority of the neonates had birth weight between 2.5 to $3 \mathrm{kgs}(45.6 \%)$ followed by 3.1 to $3.5 \mathrm{kgs}(27.9 \%)$ followed by $3.6-4.0 \mathrm{kgs} .7 .4 \%$ had birth weight less than $2.5 \mathrm{kgs}$ and only $2.9 \%$ had birth weight of more than $4 \mathrm{kgs}$. The mean birth weight was $2.7 \mathrm{~kg}$.

Out of 68 cases included in the study there were 4 cases with intrauterine fetal death. Out of 64 live births with 5 new borns required NICU admission i.e. $7.8 \%$. Of which two cases were admitted for phototherapy and three cases were admitted because of low birth weight.

Table 2: Intraoperative findings: Adhesions between uterus and anterior abdominal wall and bladder.

\begin{tabular}{lll} 
Adhesions & Number & Percentage \\
\hline Present & 29 & 42.6 \\
\hline Absent & 39 & 57.4 \\
\hline
\end{tabular}

The mean hospital stay of the cases was 8 days. In some cases, the hospital stay was increased due to postoperative complications like wound infection, wound gaping and fever. Out of total 68 cases 3 cases required resuturing of the abdominal wound.

Table 3: Placental abnormalities seen in intra operative period.

\begin{tabular}{lll} 
Placental abnormality & Number & Percentage \\
Placenta previa & 13 & 19.1 \\
\hline Adherent & 4 & 5.8 \\
\hline
\end{tabular}

\section{DISCUSSION}

The incidence of adhesions observed in present study was $42.6 \%$ which was higher than studies done by Tulandi et al, Juntanen et al but almost similar to study done by Morales el al8 as depicted in the table 5.,7 In present study the incidence of placenta previa was $19.1 \%$ which is almost similar to the studies done by Ghourab et al i.e. $22.5 \%$ and Usta IM et al i.e. $15.6 \%$ in cases with previous two lower segment caesarean section. ${ }^{9,10}$

Table 5: Incidence of adhesions observed in various studies.

\begin{tabular}{|l|l|}
\hline Studies & Adhesions \\
\hline Present study & 42.6 \\
\hline Joseph et $\mathrm{al}^{11}$ & 34 \\
\hline${\text { Morales et } \mathrm{al}^{8}}^{8}$ & 46 \\
\hline Tulandi et $\mathrm{al}^{7}$ & 24.4 \\
\hline Juntunen et $\mathrm{al}^{3}$ & 27 \\
\hline
\end{tabular}

The present study shows the incidence of placenta accreta in cases with previous two lower segment caesarean section to be $5.8 \%$. In one study done by Silver et al in 2006 states that in the presence of placenta previa the risk of placenta accreta was 3\%, 11\%, $40 \%, 61 \%$ and $67 \%$ respectively for the first, second, third, fourth, and fifth or greater repeat caesarean deliveries respectively. ${ }^{10}$
On observing the status of previous scar during intra operative period the incidence of thin lower uterine segment was observed in $16.1 \%$ which is similar to Joseph et al $11(17 \%)$ and Samar et al (18\%) but was slightly higher than study conducted by Farkhundah et al i.e $11.6 \% .^{11,12,13}$ In the present study the mean birth weight was $2.7 \mathrm{kgs}$. The birth weight according to various studies is as shown in Table 6 . In the present study it was seen that incidence of NICU admission was $7.8 \%$ which was much lower than in the study done by Rashid M. et al in which incidence of NICU admission was $20 \% .^{14}$

Table 5: Mean birth weight according to various studies.

\begin{tabular}{|c|c|}
\hline Studies & Mean birth weight \\
\hline Present study & $2.7 \mathrm{~kg}$ \\
\hline Sobande $\mathrm{A}$ et $\mathrm{al}^{15}$ & $2.970 \mathrm{~kg}$ \\
\hline Rashid M et al ${ }^{14}$ & $2.962 \mathrm{~kg}$ \\
\hline Macones GA ${ }^{16}$ & $3.392 \mathrm{~kg}$ \\
\hline Cahill AG et al ${ }^{17}$ & $2.046 \mathrm{~kg}$ \\
\hline
\end{tabular}

\section{CONCLUSION}

The present study shows that the maternal and perinatal morbidity and mortality is increased with increasing number of caesarean sections. So, trial of labour and use of labour analgesia should be promoted in order to reduce rate of primary caesarean section which can reduce the rate of placenta previa and adherent placenta in subsequent pregnancies.

\section{Funding: No funding sources}

Conflict of interest: None declared

Ethical approval: The study was approved by the Institutional Ethics Committee

\section{REFERENCES}

1. International Institute for Population Sciences (IIPS) and Macro International. National Family Health Survey (NFHS 1) 1992-93. Mumbai India: IIPS, 1995. Available from: http://www.rchiips.org/nfhs/nfhs1.shtml

2. Arnold F, Parasuraman S, Arokiasamy P, Kothari M. Nutrition in India. National Family Health Survey (NFHS-3) India 2005-06.

3. Juntunen K,MakarainenL,Kirkinen P. Outcome after a high number of repeat caesarean section.BJOG 2004;111(6):561-3.

4. Gillian M,Rosenberg D, Davis F.The likelihood of placenta previa with greater number of caesarean deliveries and higher parity.ObstetGynecol 2002;99(6):976-80.

5. Kirkenen P.Multiple caesarean sections; outcome and complications Br J Obstet Gynecol.1998;95:77882. 
6. Miller DA, CholletJA,Goodwin TM. Clinical risk factors for placenta previa- placenta accreta. Am J Obstet Gynecol.1997;177(1):210-4.

7. Tulandi TL, AgdiM, Zarei A, Miner L, Sikirica V; adhesion development and morbidity after repeat caesarean delivery.Am J Obstet Gynecol. 2009;201(1):56

8. Morales KJ,Gordon MC, Bates GW;Post caesarean delivery adhesions associated with delayed delivery of infant. Am J Obstet Gynecol 2007;195(5):461.e461-6.

9. Ghourab S, Al Jabari A.Placental migration and mode of delivery in placenta previa:transvaginal sonographic assessment during third trimester. Ann Saudi Med 2000;20(5):382-5

10. Usta IM, Hobeika EM, Meesa AA, Gabriel GE,NassarAH.Placenta previa accreta:Risk factors and complications.Am J obstetGynecol 2005;193(3):1045-9 .

11. Sheethal Joseph,Dr.Sareena Gilvaz.A comparative study on intraoperative problems during primary versus repeat caesarean section. Sch J App Med Sc, 2016;4(2A):303-10.

12. Kadem SD. Measuring lower uterine segment thickness using abdominal ultrasound to predict timing of cesarean section in women with scarred uterus at elwiya maternity teaching hospital. AlKindy College Med J. 2013;9(2):9-13.
13. Farkhundah Khursheed, Pushpa Siri Chand, Nasreen:Intraoperative complications encountered in patients with repeat caesarean section.JLUMHS 2009;08(01):76.

14. Rashid M, Rashid RS.higher order repeat caesarean sections:how safe are five or more?RCOG.2004;111(10):1090-4.

15. Sobande A,Eskander M.Multiple repeat caesarean sections:Complications and outcomes.Canada JOGC 2006;28(3):193-7.

16. Macones GA,Cahil A, Pare E,Stamilio DM, Ratcliffe $\mathrm{S}$, Stevens E et al. Obstetrics outcome in women with two prior caesarean deliveries:Is vaginal birth after caesarean delivery a viable option? Am J Obstet Gynecol. 2005;192(4):1223-9.

17. Cahill AG, T uuli M, Odibo AO, Stanilio DM, Macones DA. VBAC for females with three or more prior caesareans: assessing safety and success. BJOG 2009; 117:422-8.

Cite this article as: Singh P, Agarwal R, Yadav S. An analytical study of intraoperative, immediate post-operative and perinatal complications in previous two caesarean section. Int J Reprod Contracept Obstet Gynecol 2018;7:4239-42. 